\title{
Enterprise Resource Planning (ERP) Evaluation and Implementation: A Case Study
}

\author{
Prisca Yosevine ${ }^{\mathrm{a}}$, Raymond Sunardi Oetama ${ }^{\mathrm{b}}$, Johan Setiawan ${ }^{\mathrm{c}}$, Elfindah Princes ${ }^{\mathrm{d}}$ \\ a, b Universitas Multimedia Nusantara, Jakarta, Indonesia \\ c Monash University, Melbourne, Australia \\ d The University of Queensland, Brisbane, Australia
}

\begin{abstract}
Objective - To understand the success rate of ERP in the company by using the Ifinedo method and provide proposals that can improve ERP implementation in the company based on the unfulfilled Ifinedo method. Methodology - This research uses Quantitative method research distributed to 50 end users at Indoporcelain using surveys and interviews.

Findings - The research found one point that is less valued in the company, namely vision and mission factors in organizational variables compared to other factors. Therefore, proposals in this sector are indispensable in order to increase the success of ERP implementation in the company. Furthermore, lack of IT support due to the management's ignorance has made the ERP implementation did not reach the optimum performance expected.

Novelty - By measuring the success rate of ERP in the company, the company can know how the success rate of ERP implementation in its company. The company can make corrections and quality improvements to existing ERP systems based on proposals with unmet Ifinedo method.

Keywords: Enterprise Resource Planning; Ifinedo Method; System Quality, Information Quality; Vendor Quality

JEL Classification: C83, L60, M15

Article info: Received 15 March 2021; Revised 16 April 2021; Accepted 14 May 2021

Article Correspondence: princesselfindah@gmail.com

Recommended Citation: Yosevine, P., Oetama, R. S., Setiawan, J., \& Princes, E. (2021). Enterprise Resource Planning (ERP) Evaluation and Implementation: A Case Study. Journal of Multidisciplinary Issues, 1(1), 49-66.
\end{abstract}

\section{INTRODUCTION}

ERP is a software application system function that can help organizations in controlling business better because it can reduce stock and inventory levels, increase stock turnover, reduce cycle time orders, increase productivity, better communication and have an impact on increasing the company's benefits (Yusuf et al., 2006). The success of ERP implementation can be measured based on the things described above. In addition, the success of ERP implementation is also caused by several other factors, e.g., organizational culture, organizational environment, and good network relationships (Xue et al., 2005), costs, schedules, and objectives (Sun et al., 2005). These factors are the key to successful ERP implementation in the company, yet few neglect them. Hence, the failure in the implementation of ERP systems to carry out their business activities. For example, in 1998, Dell abandoned the ERP system made by SAP after spending approximately 115 million US dollars and has spent approximately two years on the ERP system implementation process. This system at Dell failed because it was not suitable for their products that sold different types of products and had a large sales volume. Not all companies successfully implement ERP systems to support their business activities, therefore, there is a need to evaluate ERP systems running in the company so that the company's considerable investment in the system does not become futile and can improve and support the achievement of the company's target. Indoporcelain is one of the manufacturing companies engaged in the production and distribution of porcelain that has recently adopted ERP systems 
with homemade software/applications to support the company's entire business processes created and developed by the company's IT department in the last two years since 2011. To know the success of the use of ERP in the company is a complicated thing because of the complex nature of ERP (Ifinedo, 2006). However, if this can be done then the company can evaluate the ERP system they use. The evaluation results can be used as learning materials to improve and even increase the benefits of the implementation of the system in the company.

In this study, researchers were interested in using the Ifinedo method, which has successfully measured the successful implementation of ERP system in companies in Finland. In this method, Ifinedo conducted his research in 2006 by developing the Gable model by adding two other dimensions: the quality of IT vendors /consultants in the company and the influence of group work. As explained in the background, the company's measurement of ERP success rate is needed in this study. The authors will use the Ifinedo method to measure the success rate of ERP in the company. The formulation of problems that will be discussed in this study are: (1) What is the success rate of ERP in a company using the Ifinedo method? (2) What can be proposed to the company to be able to improve the success of ERP implementation in the company based on the Ifinedo method have not been met?

\section{LITERATURE REVIEW}

\section{Information System}

Information contained in a company requires a system to be able to stream such information for corporate purposes. A system is basically a group of closely related elements, which function together to achieve a specific goal (Sutabri, 2004). A system is a group of interconnected components, working together to achieve common goals by receiving inputs and generating output in an orderly transformation process (O'Brien, 2005).

After knowing the definition of system and information, the authors want to explain information systems. An information system is a man-made system that generally consists of computer-based and manual components created to collect, store, and manage data and provide output information to users. An information system is a system within an organization that brings together the needs of daily transaction processing that supports the operational functions of a managerial organization with the strategic activities of an organization to be able to provide certain outside parties with the necessary reports (Sutabri, 2004). Based on the theory that has been presented above, it can be concluded that the information system is a system used to process data in a company into useful information for the organization.

\section{Enterprise Resource Planning (ERP)}

Some of the definitions below are ERP definitions obtained from various sources, namely:

- An enterprise-wide set of management tools that balances demand and supply, containing the ability to link customers and suppliers into a complete study chain, employing proven business processes for decision making, and providing high degrees of cross-functional integration among sales, marketing, manufacturing, operations, purchasing logistics, finance, new product development, and human resources, thereby enabling people to run their business with high levels of customer service and productivity, and simultaneously lower cost and inventories; and providing the foundation for effective e-commerce.

- A business system software package that allows companies to manage the effectiveness and efficiency of resource usage (materials, human resources, finance) by providing a total integrated solution, for the needs of organizational information processes.

- ERP system is a multi-module application software package system that integrates key business and management process across an enterprise.

- A complex IT business package is designed to integrate business processes and functions and present a holistic view of business by allowing common and performed data sharing in a real-time environment. 
Based on some of these definitions, it can be concluded that ERP is a computer software and can also be seen as a tool to help companies integrate business processes and functions in the company. In his book, O'Leary (2002) explains some characteristics of ERP systems: ERP system integrates key business processes, ERP system as a software package designed for a client-server environment both traditional and web-based, ERP systems process large transactions and the majority of an organization, ERP system uses a database for the entire company that stores each data once, ERP system allows real-time data access. In some cases, ERP allows integration and transaction processing and planning activities, supports various existing situations and multiple languages (essential for multinational companies), supports the business practices of specific industries, and can be customized without programming.

\section{Advantages of ERP Implementation}

Here are the advantages that are expected to be obtained from ERP systems, among them (Khan, 2002): (1) In terms of overall business, ERP accommodates changes in business conditions; (2) In the internal integration of the company, ERP integrates the company's information and data, combines the functions of many applications that the company needs to operate, and integrates it; (3) In terms of process, it allows the company to standardize business processes; (4) In terms of flexibility, ERP allows the addition or renewal of system components or system functional capabilities; (5) In continuous improvement, additional business processes can be implemented through ERP; (6) In terms of access to reporting and information, ERP allows the availability of standard reports but can also develop the form of reports as desired; (7) In terms of quality control, ERP minimizes errors from various functionalities through validity checks facilitated by an integrated system; (8) In terms of cost, successful ERP implementation will result in cost savings; (9) In terms of organizational performance, ERP can produce agile and responsive organizations; (10) Technically, ERP provides real-time information; (11) From the other hand, ERP can reduce tedious jobs such as matching purchase orders and invoices; (12) ERP can also provide a user friendly interface.

\section{Challenges of ERP Implementation}

Its implementation is very difficult because of its integrated implementation, so organizations must support the effectiveness of its implementation by changing the way they do business. Some of the disadvantages of ERP are as follows (Sumarna, 2006): (1) High expense. Installation of ERP solutions for large companies costs millions, even up to tens of millions of EUROS. In addition, it is also necessary to take care of ERP software. (2) Failure rate. An independent study indicates that 40 percent of all ERP systems are only partially implemented and that 20 percent of ERP implementations fail miserably (Trunick, 1999). Another study explained that the probability of ERP failure rate is more than 50 percent. (3) High transfer costs. ERP implementation requires the process of moving from the old system to the new system. Moving from a functional and fragmented information system to an integrated information system with one database requires a large cost, especially for infrastructure, data conversion, and others. (4) Difficult to use. ERP solutions are very complex and require employees with many skills to set them up. (5) Takes a long time. Customizing an ERP system for some organizations is very expensive and takes a long time. This means that ERP implementations must be well planned in advance. (6) Refusal to share sensitive internal information. It is necessary to clearly define the access, scope, and responsibility of the ERP system and the renewal of the relevant rules.

Based on the problems that occur, ERP implementation problems faced by companies can be divided into two types, namely managerial problems and technical problems (Themistocleous et al., 2001). Managerial problems that companies often face during implementation and after implementation are as follows (Themistocleous et al., 2001): Conflicts with business strategies, conflicts with consultants, conflicts with vendors, internal conflicts, project costs that exceed budgets, late project completion times, employee resistance to change. The following are the technical problems that companies often face are (Themistocleous et al., 2001): Customization, foreign exchange rates, integration with existing systems, integration with other applications, security, Y2K. In implementing ERP, the company passed several 
stages of ERP implementation called ERP life cycle (O'Leary, 2000): Decided to use ERP, Choose ERP system, Design ERP system, Apply ERP, Go Live, Training using ERP.

When companies decide to use ERP, they aim to analyze their reasons for making decisions on ERP implementation. In general, there are four reasons why companies carry out implementation, among them (O'Leary, 2000): Business process reasons, Competitive reasons, Technology reasons, Strategic reasons. After that the company chooses the ERP system to be implemented. There are two analyses commonly done by companies, namely needs analysis and gap analysis. Both analyses have their own advantages and disadvantages (O’Leary, 2000).

Next is the stage of designing ERP system that the company will use. At this stage, the problems facing the company are business processes that have to change or ERP software that has to adapt to the business processes that exist in the company. This change is known as "r-small" for small change and "R-large" for big change (O'Leary, 2000). Changes that can occur are changes to the software, changes in the process, whether it is just one of them or both, are adapted to the company's circumstances. Such changes are not an optimal solution. All changes depend on a number of variables in the company. For example, in a type of industry, some companies have to use "R-large" changes to be able to grow, but in the same type of ERP industry and software can occur, there are companies that only need "r-small" changes.

In implementing ERP, the company assesses which methodology is the most optimal and the methodology that is most suitable for the company. But in reality there is no most optimal methodology. All methodologies must be adapted to the existing company conditions. Each company must consider factors such as company size, complexity, control, and corporate hierarchy in order to determine what methodology the company should use (O'Leary, 2000).

Go Live, the implementation team must steer the company through the stabilization period in the next stage. The company must determine what needs to be done and renovated. For example, data conversion and documentation all need to be evaluated to ensure that they meet the needs of the company. Companies also need to compare their planning before ERP implementation is done with what is actually happening to determine the extent to which the implementation was successfully carried out. Companies should also look to the future to find out what improvements should be made in the future, whether it is necessary to create a new system or procedure, and what extensions to do for ERP systems, if any. Many companies do not provide an adequate budget for the implementation of tasks after ERP implementation or this go-live stage (O'Leary, 2000). To ensure that project management can complete this ERP life cycle completely, an adequate budget is required to ensure project resources can be met throughout the project.

\section{ERP Implementation Success}

Basically, ERP implementation is different from the implementation of traditional information systems in scale, scope, complexity, organizational change, project costs, and the need to reengineering business processes (Sumarna, 2006). The measure of successful implementation is usually in the form of evaluation system, technology assessment, and the influence of ERP on the objectives of the company or organization that implements it (Sumarna, 2006). Researchers or practitioners have put forward various definitions of successful ERP implementation from various but related fields. The definitions of success of ERP implementation are as follows: successful use of information systems in achieving organizational efficiency and effectiveness (DeLone \& McLean, 2003), success includes success in organization, successful implementation of projects and successful technical implementation (Wixom \& Watson, 2001), optimal success refers to the outcomes that organizations can achieve with ERP (Markus \& Tanis, 2000), successful utilization or utilization of ERP systems in achieving corporate goals (Ifinedo, 2006), Successful assessment can be seen from different dimensions, consisting of (Shanks et al., 1999): success viewed in technical terms, success viewed in economic, financial, or strategic business terms, success viewed in term of smooth running of business operation, success viewed by ERP-adopting organization's managers and employees.

The assessment of a project can be viewed in two different ways. First, a project can be said to be successful if the project has qualified to run, such as meeting the deadline, being within the planned budget, 
and achieving the system performance as expected. Second, the successful implementation of ERP can be defined as the effectiveness of the use of costs on the integration of business processes as a whole using information technology. Companies are satisfied with their ERP software with a variety of productivity improvements, including process automation, improved efficiency, stronger integration and procedure reduction (Lian, 2005). The best results an organization can possibly achieve with an "enterprise system," with available business situations, are measured by comparing them to project portfolios, initial operations, and measures of long-term business success (Esteves et al., 2003).

\section{Evaluation and Measurement of ERP Implementation}

There is actually no method of measuring the success of standard ERP implementations. This problem is caused because the ERP system success meter method is still evolving over time. The measurement methods produced by researchers or practitioners in the field of information systems are generally an improvement over previous measurement methods. The authors will use the method resulting from Ifinedo research to conduct this research to measure ERP implementation success in Indoporcelain. This method is the most recent method in measuring the success of ERP implementation.

The Ifinedo method uses a different approach than the models or frameworks used by other researchers. In his method, Ifinedo categorizes variables into two parts, namely organizational variables and IT-related variables. This section is used to assess the success of ERP system implementation with existing variable sets (Ifinedo, 2006). Ifinedo method departs from the method resulting from the results of previous research conducted by Gable et al. (2003).

Ifinedo makes the Gable measurement method the main basis because it is the most widely recognized method compared to other methods. This method has been awarded amcis 2003, ICIS 2004 and became the best journal in the journal issued by MIS. The method initiated by Gable et al. (2003). As a model of measuring the successful implementation of ERP systems, Ifinedo adds two new dimensions, namely Workgroup Impact and Vendor/Consultant Quality.

Ifinedo added the impact of the group's work to its measurement method based on research conducted. Myers et al. (1997) argue that methods for assessing the success of an information system should include organizational impact because work teams or workgroups contribute to an organization's productivity. The philosophy underlying the ERP system, namely harmonization and integration of organizational functions and business processes, is the basis of my argument (Myers et al., 1997).

Markus and Tanis (2000) argue that the role and quality of vendors or consultants throughout ERP implementation are essential to ERP success. Markus and Tanis highlighted "dependence on vendors" as the main issue that distinguishes the implementation of this ERP system from the implementation of other IT technologies (Markus \& Tanis, 2000). Ko even highlighted the role of vendors/consultants in transferring knowledge to organizations during ERP implementation (Ko et al., 2005). The differences in measurement dimensions assessed in the Gable measurement method and the Ifinedo measurement method can be seen in Table 1.

Table 1. The differences between the Measurements of Gable and Ifinedo

\begin{tabular}{llcc}
\hline \multicolumn{1}{c}{ Objective of Dimension } & \multicolumn{1}{c}{ Dimension of Success } & Gable (2003) & Ifinedo (2006) \\
\hline Evaluation of System Quality & System Quality & $\checkmark$ \\
Evaluation of information quality produced by the & Information Quality & $\checkmark$ & $\checkmark$ \\
system & Vendor/Consultant Quality & & $\checkmark$ \\
Evaluation of service quality obtained by the user & Individual impact & $\checkmark$ \\
Evaluation of influence on individuals & Workgroup Impact & $\checkmark$ \\
Evaluation of influence on workgroups & Organizational Impact & $\checkmark$ & $\checkmark$ \\
Evaluation of influence on organizations & Overall Impact /ERP success & $\checkmark$ & $\checkmark$ \\
Achievement indicators & & \\
\hline
\end{tabular}




\section{Organization and IT Variables}

In the Ifinedo method, the variables that affect ERP implementation success in a company are organizational variables and IT variables. Organizational variables are more about the situation of the existing organization. Here are the factors in this variable: Top Management Support, Vision and Mission, Organizational Size, Organizational Structure, Organizational Culture. To make it easier to measure the success of the successful dimension, Ifinedo divides the dimensions of success into even smaller criterias which can be seen in Table 2.

Tjahjadi (2008) found that ERP success factors in Indonesia are similar to ERP success factors in Ifinedo success assessment method. Tjahjadi (2008) concluded that Ifinedo's successful method can provide a good view of variables that can be a factor in the successful implementation of ERP systems in Indonesian companies. The variables contained in the method can represent all factors in the implementation of ERP systems in Indonesia. Therefore, researchers used the Ifinedo method as a reference method used in this study.

\section{Indoporcelain}

Indoporcelain is a company engaged in the manufacturing industry of furniture and furnishings and household products, with major production for ceramics. Indoporcelain is one of the largest ceramic producers in Indonesia that serves import and export distribution with major export markets in North America, Scandinavia, and Western Europe. Indoporcelain conducts activities ranging from production to distribution. This company has achieved ISO9002, ISO9001:2000, ISO9000:2008 certification standard, and C-TPAT certification. Indoporcelain also serves OEM (Original Equipment Manufacturer) for some well-known products such as serving production for KFC plate needs, glass and plate needs for J.Co and many other products. The company has more than 800 workers, started its own ERP implementation in 2011 and allocates a budget of less than $3 \%$ a year for IT.

Table 2. The Six Dimensions of Successful ERP Implementation

\begin{tabular}{|c|c|c|c|c|c|}
\hline $\begin{array}{l}\text { System } \\
\text { Quality } \\
\end{array}$ & $\begin{array}{c}\text { Information } \\
\text { Quality }\end{array}$ & $\begin{array}{c}\text { Vendor/Consultant } \\
\text { Quality }\end{array}$ & $\begin{array}{c}\text { Individual } \\
\text { Impacts }\end{array}$ & $\begin{array}{c}\text { Workplace } \\
\text { Impact }\end{array}$ & $\begin{array}{c}\text { Organizational } \\
\text { Impact }\end{array}$ \\
\hline Data accuracy & $\begin{array}{l}\text { Up to date } \\
\text { information }\end{array}$ & $\begin{array}{l}\text { Adequate technical } \\
\text { support }\end{array}$ & Ability to learn & $\begin{array}{l}\text { Increase in } \\
\text { participation }\end{array}$ & $\begin{array}{l}\text { Solution } \\
\text { effectiveness }\end{array}$ \\
\hline $\begin{array}{l}\text { System } \\
\text { flexibility }\end{array}$ & Timeliness & Credible and trusted & $\begin{array}{l}\text { Individual } \\
\text { productivity }\end{array}$ & $\begin{array}{l}\text { Increase in } \\
\text { communication } \\
\text { reach }\end{array}$ & Cost reduction \\
\hline Ease of use & $\begin{array}{l}\text { Easy to } \\
\text { understand }\end{array}$ & Good relationship & $\begin{array}{l}\text { Individual } \\
\text { benefits }\end{array}$ & $\begin{array}{l}\text { Increase in } \\
\text { coordination }\end{array}$ & $\begin{array}{l}\text { Increase in overall } \\
\text { productivity }\end{array}$ \\
\hline Easy to learn & Usefulness & $\begin{array}{l}\text { Experienced and } \\
\text { provide qualified } \\
\text { trainings }\end{array}$ & $\begin{array}{l}\text { Decision- } \\
\text { making quality }\end{array}$ & $\begin{array}{l}\text { Task } \\
\text { responsibilities }\end{array}$ & $\begin{array}{l}\text { e-Business or e- } \\
\text { commerce } \\
\text { possibility }\end{array}$ \\
\hline Reliability & Clarity & Good communication & Time-saving & $\begin{array}{l}\text { Department } \\
\text { Efficiency }\end{array}$ & $\begin{array}{l}\text { New competitive } \\
\text { advantages }\end{array}$ \\
\hline $\begin{array}{l}\text { Data } \\
\text { integration }\end{array}$ & Relevance & & & $\begin{array}{l}\text { Increase in } \\
\text { management } \\
\text { productivity }\end{array}$ & $\begin{array}{l}\text { Increase in } \\
\text { customer } \\
\text { satisfaction }\end{array}$ \\
\hline $\begin{array}{l}\text { User } \\
\text { requirement }\end{array}$ & Availability & & & $\begin{array}{l}\text { Problem solving } \\
\text { effectiveness }\end{array}$ & $\begin{array}{l}\text { Business process } \\
\text { change facility }\end{array}$ \\
\hline $\begin{array}{l}\text { Efficiency } \\
\text { system features }\end{array}$ & & & & & $\begin{array}{l}\text { Decision-making } \\
\text { Better use of } \\
\text { information sources }\end{array}$ \\
\hline
\end{tabular}




\section{RESEARCH METHODOLOGY}

In this study, researchers end-users of ERP software in the company are respondents in the study. The total end-users listed in this study numbered 50 people. Researchers hope that these 50 end users can describe the success of ERP implementation in Indoporcelain. The questionnaire used in this study is a questionnaire obtained from the Ifinedo method. This questionnaire has standard questions in English. Therefore, the preparation of questionnaires is only done by translating the questions in the questionnaire into Bahasa Indonesia. The authors also gave one additional questionnaire to the company's IT Manager to get information about the company.

The data collection stage is divided into 2 parts, namely testing the questionnaire used and processing data from the questionnaire results obtained. In the questionnaire testing phase, researchers used data adequacy test using SPSS 18.0 program, namely: (1) Validity Test. Used to state the extent to which the data contained in a questionnaire will measure what you want to measure. (2) Reliability Test. Determine the extent to which a measurement result is relatively consistent when the measuring instrument is used repeatedly. If the test results state that the data is eligible, then the data can then be processed. Data processing is done by recapitulating general data from the questionnaires given to respondents, recapitulating the assessment data of questionnaire results, finding success scores, and conducting correlation tests on each variable and dimension that exists with the help of the SPSS.

The final stage of this study contains the analysis of data from the results of data processing obtained at the previous stage, concluded research, and advice for the company and subsequent research. At this stage, the authors will analyze the data that has been obtained from research in the form of questionnaire answer results with the help of SPSS software to determine the success rate of ERP usage in this company and compare results between each variable. From the results of this analysis, the authors will get the results of each variable tested. Based on these results will be obtained what factors hinder and support the implementation of ERP in Indoporcelain.

In addition to analysis using the values of each variable factor, analysis will also be conducted to analyze the correlation test results. The analysis will connect between variables with each other or between successful dimensions with other successful dimensions. From the results of this analysis, there will be variables or dimensions with a strong and weak relationship and the possibility of each factor affecting each other. From the analysis conducted, the researchers expect to find what factors support the success of ERP implementation or problem-solving of each variable that causes the ERP implementation to be not optimal. Problem Solutions will be proposed to companies to improve the success of ERP implementation in their companies.

In this study, the dissemination of questionnaires was conducted at only one company. This aims to make the research more focused on assessing ERP system implementation in one company. The interesting thing about this company is that the company makes the ERP system of this company. They do not use outside vendors to facilitate the company's performance, but they, especially the IT department in pt companies. Indoporcelain developed ERP software to support the company's business processes. In the data collection, the distribution of questionnaires was conducted to a number of employees. The distribution of questionnaires was conducted to all end users of 50 respondents and researchers themselves conducted this dissemination. Because the researchers jumped directly into the field to provide explanations about questionnaires to respondents, then based on the data obtained a questionnaire that is eligible to be 50 people.

\section{Company Profile}

General data collected is obtained in two ways, namely direct observation and question and answer with respondents, as well as the results of questionnaires that are general data of respondents. The Ifinedo questionnaire was initially intended to assess ERP implementation success for a number of companies simultaneously. In contrast, for this study, the Ifinedo questionnaire was used to assess ERP implementation 
success in only one company. General data asked include the respondent's department in the organization, length of work, gender, age, respondent's view on the stability of the company, and the respondent's view of the level of competition of the company with other companies. The largest percentage of long-employed respondents were over 7 years old at a percentage of 46\%, the remaining 30\% had worked between 5-7 years, then $14 \%$ had worked for 3-5 years, and $10 \%$ of respondents had worked for 1-3 years. Based on the research on the reality encountered in the field, most employees are comfortable with the work environment in this company, so many of the employees who have served for a long time in this company. In addition, the employee's length of work also helps the accuracy of the answers on the questionnaire.

Based on the results of the questionnaire can be seen most employees who work at this company aged between 31-40 years. A total of 50\% of employees are aged 31-40 years, then 28\% are 21-30 years old, $16 \%$ are 41-51 years old, and 6\% are over 51 years old. Age 21-40 years is the age of the majority of employees who work in this company. accept new things. The next general data is about the department of the respondent. Respondents came from various departments within the company, which means that the department is active in ERP use in the company. In addition, respondents were also asked questions related to their assessment of the company's ability to compete and the stability of the company in the midst of market competition. A total of 52\% (26 respondents) stated that the company is very competitive to the surrounding business environment, $26 \%$ (13 respondents) think the company is quite competitive, and the rest think the company is competitive to the surrounding business environment. About the stability of the company. A total of $44 \%$ (22 respondents) stated that the company is very stable, $38 \%$ (19 respondents) think the company is quite stable, and the rest think the company is stable. This result is obtained from respondents who have worked for a long time in the company, therefore this data is not the original filling of the respondent but is the result of what respondents feel during their work at this company.

After filling in the data on the profile of respondents and companies, the next stage is the filling of assessment of ERP systems running in this company based on the dimensions of success of IFINEDO ERP implementation. At this stage, respondents will give an assessment from a scale of 1 (one) to 7 (seven) on each statement in the questionnaire. The higher the value given by respondents, the better ERP system used by the company.

\section{FINDINGS AND RESULT}

Data processing is divided into several parts: reliability test, validity test, success test, and successful dimension correlation test. The existing data will be valid if the corrected item-total correlation is more than 0.279 . The value of 0.279 was obtained from the table of $r$ product moment values with a significant level of 5\% (Sugiyono, 2004) and respondents of 50 people. Reliability tests are used to test the consistency of respondents' answers. In testing reliability, researchers used the results of SPSS, which is Cronbach's alpha value as the reference value. An instrument is said to be reliable if its reliability test value is greater than 0.700 (Uyanto, 2006) and if the value is smaller than that value, then the instrument is said to be not reliable. An alpha value of 0.876 can be considered reliable because it is above the minimum limit of 0.700 . The questionnaire has passed the validity test and reliability test, after passing both tests, it will be processed to get the success value of ERP system implementation used by the company. Questionnaire processing is done by summing the score of each criterion obtained from the respondent's answer results based on the Likert scale and then will be averaged so that the ERP implementation success score will be obtained. The recapitulation of the calculation of each variable and the successful dimensions of the ERP can be seen in Table 3.

From the above results can be seen that the success of ERP implementation in Indoporcelain is 5.2745 or 5.28 from a scale of 1 (one) to 7 (seven) with an organizational variable value of 5.1091 and an IT variable of 5.2743. The value of the company's success in implementing its own ERP system compared to Ifinedo's research conducted in 2006 in Finland and Estonia is quite large. The success rate in both countries 
is 4.88 (Ifinedo, 2006). From this value, it can be said that ERP implementation in this company is better than the success in both countries.

Table 3. Measurement Table of Success Factors Value

\begin{tabular}{lcc}
\hline \multicolumn{1}{c}{ Factors } & $\mathrm{N}$ & Mean \\
\hline ORG (Organization) & 50 & 5.1091 \\
IT & 50 & 5.2743 \\
NK (Success Factors) & 50 & 5.2745 \\
DKS (System Quality) & 50 & 5.1236 \\
DKI (Information Quality) & 50 & 5.3500 \\
DKV (Vendor Quality) & 50 & 5.7720 \\
DDI (Individual Impact) & 50 & 5.1933 \\
DDK (Workgroup Impact) & 50 & 5.1067 \\
DDO (Organizational Impact) & 50 & 5.2800 \\
\hline
\end{tabular}

The next data processing conducted in this study was a correlation test to determine the magnitude of the relationship or correlation between variables or dimensions with another variable or dimension. The magnitude of the relationship or correlation that exists between one variable or dimension with another variable or dimension is determined by looking at the coefficient obtained. The coefficient values obtained will range between 0 and 1 . The higher the value obtained (close to 1 ) the stronger the relationship or correlation between variables or dimensions, and vice versa. (Nugroho, 2005).

Table 4. Correlation Test Result Between Variables and Success Factors Dimension

\begin{tabular}{lccc}
\hline & ORG & IT & NK \\
\hline ORG & 1.000 & 0.523 & 0.535 \\
IT & 0.523 & 1.000 & 0.556 \\
NK & 0.535 & 0.556 & 1.000 \\
\hline
\end{tabular}

As seen in Table 4, there is a correlation between variables and success values. The correlation between the organizational and success value is 0.535 , which indicates a strong relationship between the two. While the correlation for IT variables and success values, the correlation value is 0.556 which is slightly higher than the organizational variable. Based on these values, it can be concluded that the correlation between the two is equally strong.

Table 5. Correlation Test Result Between Dimensions and Success Factors' Values

\begin{tabular}{cccccccc}
\hline & NK & DKS & DKI & DKV & DDI & DDK & DDO \\
\hline NK & 1.000 & 0.801 & 0.734 & 0.768 & 0.813 & 0.806 & 0.719 \\
DKS & 0.801 & 1.000 & 0.736 & 0.562 & 0.544 & 0.553 & 0.507 \\
DKI & 0.734 & 0.736 & 1.000 & 0.528 & 0.533 & 0.504 & 0.517 \\
DKV & 0.768 & 0.562 & 0.528 & 1.000 & 0.555 & 0.509 & 0.507 \\
DDI & 0.813 & 0.544 & 0.533 & 0.555 & 1.000 & 0.779 & 0.676 \\
DDK & 0.806 & 0.553 & 0.504 & 0.509 & 0.779 & 1.000 & 0.673 \\
DDO & 0.719 & 0.507 & 0.517 & 0.507 & 0.676 & 0.673 & 1.000 \\
\hline
\end{tabular}

According to Ifinedo, there are 6 dimensions of success to assess the success of the company's ERP implementation. Researchers have conducted correlation tests between these 6 successful dimensions and the success value (NK) of ERP implementation. From the results of the correlation test obtained results in the form, the system's quality dimension has a robust correlation with a success value (NK) with a value of 0.801 (see Table 5). The system's quality is the flexibility of the ERP system, ease of use, ease of learning, 
reliability, efficiency, features owned, ease of integration of data with other IT systems, ease of customizing and meeting the needs of its users. These basic capabilities are the initial consideration when companies choose ERP software. This capability is considered based on the company's existing conditions. If ERP does not fulfil this basic capability, then the implementation can run with no maximum.

Companies should be able to choose ERP software that suits the company's condition, as evidenced by the high correlation value between the information quality dimension (DKI) and the system quality dimension (DKS) which is 0.736 . The selection of ERP software should also be done in consultation with ERP consultants/vendors. The consultation will be very useful because ERP vendors /consultants can be said to be the organization/person who best understands the existing ERP system, and proven by the considerable correlation value between DKV and DKS, which is 0.562. By choosing ERP software that suits the company's condition, the ERP implementation can run to the maximum, and the possibility of ERP implementation failure can be minimized from the beginning.

Then another interesting thing to discuss is the correlation between individuals (DDI) and working groups (DDK). This is interesting to discuss because each company consists of departments and each department consists of individuals, the correlation between the two looks quite strong which is 0.779 . As for the correlation between DDI and DDO is 0.676 and the correlation between DDK and DDO is also 0.673. Both have almost the same correlation; this also reinforces the fact that relationships between individuals, working groups, and organizations are inseparable because organizations consist of multiple working groups and group work consists of several individuals. So the conclusion that can be drawn is that increasing the impact on individuals will also increase the impact on the group's work. The impact on the group's work will increase the impact on the organization.

The dimension of success that has the highest correlation with the value of success is DDI (Individual Impact Dimension) which is 0.813 . This proves that ERP success is more due to the selection of ERP that suits the company's condition, not because of the quality of vendors/consultants (but it is also one of the success factors) or other variables, but rather the impact on individuals. The greater the impact on individuals, the greater the impact on group work, the greater the impact on the organization and the greater the ERP implementation carried out by the company.

Comparing the correlation results between the dimensions of success with each other encountered the lowest correlation of 0.504 , which means that each existing successful dimensions have a strong correlation with the other. Table 6 shows the result of the values of each successful dimension. With the average dimension of success is above 5, which means having a good enough success because it is close to the number 7 (maximum value on the Likert scale).

Table 6. The average of Success Factors' Dimensions

\begin{tabular}{ccc}
\hline Factors & $\mathrm{N}$ & Total \\
\hline DKS & 50 & 5.1236 \\
DKI & 50 & 5.3500 \\
DKV & 50 & 5.7720 \\
DDI & 50 & 5.1933 \\
DDK & 50 & 5.1067 \\
DDO & 50 & 5.2800 \\
\hline
\end{tabular}

\section{Organisation Variable}

Based on the framework that Ifinedo created, organization variables and IT variables affect the value of successful dimensions. From the correlation test that has been conducted, it was found that the correlation value between the organization variable (ORG) and the success value (NK) of 0.535 , when compared to the correlation value between the IT variable and the success value (NK) of 0.556 , differs only slightly. 
Table 7. The Factors' Value in the Organizational Variable

\begin{tabular}{lcc}
\hline Factors & $\mathrm{N}$ & Total \\
\hline Top Management Support & 50 & 5.40 \\
Vision and Mission & 50 & 4.30 \\
Organizational Structure & 50 & 5.88 \\
Organizational Culture & 50 & 5.30 \\
\hline
\end{tabular}

Table 7 shows the results of the factors present in the organization variables. The highest value is seen in the organizational structure. A conducive organizational structure has a positive relationship with the successful implementation of ERP (Ifinedo, 2006). The organizational structure clearly supports the successful implementation of ERP. An indicator of the organizational structure of the Ifinedo assessment is a clear division of tasks. Just like ERP principles that work to integrate different tasks, task sharing, and clear task work are important in the successful implementation of ERP.

The second-largest factor is DTM (Top Management Support). This factor also greatly influences the success of ERP in the company. Top management support has a positive relationship with the effectiveness or success of information systems (Thong et al., 1996). This is due to the influence and role of top management within the company to provide financial resources and provide relevant guidelines or guidance for the success of IT projects (Thong et al., 1996). To implement ERP on the company, of course, approval from the top management is required. Approval from top management is not easy to obtain. Because basically as described above, ERP implementation in the company requires not a small amount of funds. Top management needs to consider the funds to be spent and the results to be obtained. They will tend to think that whether the use of ERP will provide a greater profit when compared to the use of the system that was already in force at that time. Not to mention the fact that not all organizations successfully implement ERP on companies. Within the framework of Ifinedo, it ensures that the company supports the company's adoption and use of IT applications.

The next factor is organizational culture; this factor gets a score of 5.3. A conducive organizational culture has a positive relationship with the successful implementation of ERP (Ifinedo, 2006). When implementing ERP, the challenge for companies is how to create a good culture so that ERP implementation can be successful. Organizational culture determines how employees work in the company. A good organizational culture can be created by instilling company values and norms in employees and making clear rules that are well communicated to all employees. Thus, employees can work well under existing procedures so that the work becomes organized and neatly organized. Assessment on the Ifinedo method assesses the documentation of procedures, information sharing, changes in work systems, employee collaboration, and clear norms and values. At Indoporcelain, this is getting a fairly high rating. Next is the vision and mission factor of the company that gets a score of 4.3. The authors will discuss this lack of value in the proposed improvements.

\section{IT Variable}

Based on correlation tests, IT variable has a slightly higher correlation than organizational variables to ERP success values. The correlation of the IT variable with ERP success value is slightly higher than the organization variable correlation with the value of ERP success with a correlation value of 0.556 . A correlation value of 0.556 based on a parameter has a strong assessment meaning it has a strong relationship with the value of success. In this study, the IT variable had a value of 5.27.

The value of the IT department turned out to get the highest score of 5.72 (see Table 8). This indicates that the IT department in their company is important to support the activities of the company. The high value of IT departments for companies makes the IT team able to keep up with the competence of IT staff to answer the needs of the company. The competence of IT staff in the company is very influential in the 
successful implementation of ERP systems. The more IT experts owned by the company, the greater the ERP implementation can be successful. IT staff can handle the problems directly when IT staff are getting more expert than problems related to ERP and other IT problems. As well as the benefits offered by ERP implemented can be more widely used because the end-user of the ERP understands and masters the overall functions of ERP and faster to know the system applied in the company. In this case, Indoporcelain already has IT staff who are reasonably competent in their fields with the results obtained from the assessment of Ifinedo method of 5.68 .

Table 8. The Factors' Value in the IT Variable

\begin{tabular}{lcc}
\hline Factors & $\mathrm{N}$ & Average \\
\hline IT Skill & 50 & 5.68 \\
IT Department Size & 50 & 4.44 \\
IS Budget & 50 & 4.44 \\
Previous System Satisfaction & 50 & 5.60 \\
IT Department Value & 50 & 5.72 \\
\hline
\end{tabular}

The next assessment is satisfaction with the old system. Based on the assessment of the Ifinedo method, Indoporcelain scored 5.60. That means they are quite satisfied with the use of the old system. This high value is due to ERP implementation in this company is still only done for the last 2 years. Nevertheless, it also shows a considerable indication of satisfaction with the old system. The level of satisfaction with the old system can be an obstacle for ERP implementation, which is when employees are familiar with the old system and do not want to change to a new system. However, the more employees are satisfied with the old system, the more they want a better system than the old system, and ERP always offers a better system (Ifinedo, 2006).

The assessment has the same number of 4.44 owned by the IT department size factor and budget for information systems in the company. The lowest number of factor assessments in IT indicates the need for improvements in the sector to support the successful implementation of ERP in this company. This will be discussed further on the proposed improvement of IT variables.

\section{External Environment}

Another variable that can affect the dimensions of success is the external environment. Although the influence of this external environment is not large, it can also be considered to adapt ERP implementation to the external environment. These variables are the type of industry, industrial climate, and country's economy (Ifinedo, 2006).

Stable industrial environment conditions do not need to use a complex IT system because companies do not need to be afraid of competition with other companies. Changes in the industrial environment that occur are also not so fast (Grover \& Goslar, 1993). This type of industry is also the next variable. In ERP implementation, industry type influences in determining ERP suitable for use by companies, because not all ERP is suitable to be implemented in all types of industries (Ifinedo, 2006). The last variable is the national economy of a country. This variable influences the perception of ERP success rate obtained (Ifinedo, 2006). The perception of ERP success obtained can vary by country.

\section{Proposed ERP Implementation Improvement}

Based on correlation analysis and variable analysis that has been discussed in the previous subsections, it can be given several proposed improvements that the company can do to carry out ERP implementation so that the implementation can be successful. If the company decides to implement ERP, then the company should be able to make its corporate environment conducive to ERP. In this improvement proposal, the authors provide a proposed improvement based on the assessment for values that are still lacking based on 
the Ifinedo method. The authors also provide the proposed organizational variables and ideal IT variables in the company so that the use of ERP can run to the maximum.

\section{Proposed Improvement of Organizational Variables}

Based on research conducted by researchers, there is 1 point that gets less value in the company, namely vision and mission factors in organizational variables. This factor reached 4.30 in the assessment of the Ifinedo method. Vision and mission factors get the lowest score on organizational variables when compared to other factors. Therefore, proposals in this sector are indispensable in order to increase the success of ERP implementation in the company. In the assessment of ifinedo, what is asked is whether the company's application supports the company's vision and whether the company's application supports the company's mission. The lack of value in this sector can be caused by the company's lack of maximum socializing the company's vision and mission. Especially when the ERP implementation may be done, management may feel that the vision and mission do not have too much effect on the ERP system so that they do not socialize this to IT consultants who make systems in the company. This is evident from the value of 4.3 in the assessment of the Ifinedo method.

Whereas many companies do ERP implementation with one of the objectives is to fulfill the vision and mission of the company (Davenport, 2000). Many companies fail to implement ERP because they do not have clear objectives related to the company's vision and mission (Davenport, 2000). The company's objective in implementing ERP must be clearly defined because ERP is more than just an IT system that companies can use, but ERP is an IT system that requires strategic clarity from a company before the ERP is implemented (Davenport, 2000).

The above theories are enough to explain how dangerous ERP systems are running without a clear vision and mission. The proposed improvement in this sector is the need to socialize the clear vision and mission of the company. Perhaps not only IT consultants are less clear about the vision and mission of the company, but other employees also have minimal knowledge about the vision and mission of the company. Therefore, top management must create a strategy so that all employees can work to fulfill the vision and mission of the company instead of just working to meet the obligations of working hours only. In addition, top management also needs to discuss with the company's IT consultants so that the application can run not only to meet the needs of the company but also to meet the vision and mission of the company. It should be a discussion with an IT consultant about the vision and mission of the company conducted when planning the creation of the company's ERP system from the beginning.

\section{Proposed IT Variable Improvement}

On the size factor of the IT department, Indoporcelain has a very small IT team, which is only 4 people, they consist of one programmer, one database analyst, one network operator, and another person who helps backup for programmers and database analysts. They are the ones who handle the whole system that runs in this company. Of course, this number is very small and inadequate to handle information systems at companies that produce and serve the import and export of ceramics. There is actually no theory to determine how much the ideal number of personnel in a department, but in this case, 4 personnel from the IT team is certainly very lacking for a company that has a branch office and serves export and import sales.

The advice from researchers is that the number of IT personnel in the IT team should follow the size of the company as well as the scope of work done by the IT team. There are not enough 4 people who do these tasks; if a person is unable to attend while there are problems that must be addressed at this time, then the coordination of work will not be maximized. It takes some people in this team who work as a team to back up the work of other team members, if the company has a branch office elsewhere that also uses the company's ERP then it is better in each branch placed IT people who can directly intervene when there is a problem that occurs, so that solving problems more effectively and efficiently.

Companies need to recruit new employees to help the IT department, because of course a lot of work from the IT department considering they themselves make ERP systems in this company. Starting from 
building ERP system to training for end-users of this system in the company and maintaining this system (where they handle bugs in this application). Of course, with the increase of competent employees for this department will certainly maximize the performance of the department and support the successful implementation of ERP in this company. However, until now, proven skill reliability of its department members in this company, although members of this department are few but can develop ERP systems and assess the success of ERP implementation in this company, reached 5.27 from a scale of 7. Of course, if added new employees who are competent in the IT field will increase the value of successful ERP implementation in the company.

The next assessment is the budget for information systems in the company. As previously stated that ERP implementation requires a small fee. However, in Ifinedo's assessment, the budget for the company's information system reached 4.4. This figure indicates that the budget for information systems in this company is not very large. This may be due to ERP systems that have not been so complex given the small number of IT departments that cause them to create the main functions used in general only. The researcher's proposal in this case is that the IT team reanalyze what features are needed in the company to maximize the use of ERP in the company. Given the support of top management who received a reasonably high assessment, so that IT financing gets a fairly important position in the agenda of improving ERP implementation in the company.

\section{Ideal Organizational Variables}

Before implementing ERP, companies should be able to know clearly why they are implementing ERP. After knowing the reason for ERP implementation, the company should be able to set the objectives of the implementation based on the reason for ERP implementation. The objectives should not be contrary to the vision of the company's mission. If the objectives are contrary to the vision and mission of the company, then the chances of success of ERP implementation will decrease. In addition to being in accordance with the vision and mission of the company, the objectives of implementing ERP must be clearly informed to all employees of the company from the top management to the lowest level. This can be done by meeting with several representatives of the company's workers to discuss the purpose of the company's implementation. Thus employees know and understand the purpose of ERP implementation and they can know what will be done by ERP implementation management and project team. By providing clear information about the purpose of the implementation, all employees can be happy to accept the presence of ERP. That way all employees will support ERP implementation. With this support, the success rate of implementation will increase.

One of the support that is quite important and should not be ignored in ERP implementation is top management support. Top management should be able to provide full support for ERP implementation truly. Full support provided by the top management is not only provided at the time of implementation but when ERP implementation planning is carried out, full support from the top management must also be provided, even after ERP implementation, the support must also be able to remain provided.

Support from top management can be done by providing support of all the resources needed for ERP implementation, especially financial resources. These resources are needed by the IT department so that the IT department can complete the entire ERP implementation life cycle project completely. By completing the project completely, the IT department can improve the success of ERP implementation.

In addition to providing the necessary resources for ERP implementation, top management can support ERP implementation by providing instructions for ERP implementation. These instructions can be done by having regular meetings with ERP implementation project leaders. That way management can know the development of the ERP implementation process and problems that occur to provide inputs to overcome these problems. The inputs submitted by management can increase the success of ERP because with these inputs ERP implemented will be more following the condition of the company considering that who knows everything about the condition of the company is top management. 
Another factor that needs to be considered so that the company is conducive to ERP survival is the organizational structure. ERP systems can serve as a tool to assist management in making decisions. So it takes flexibility for management to be able to provide information. With this flexibility, ERP can run well so that all the information needed by ERP to help management in making decisions can be obtained.

In addition to the lack of freedom of information exchange, ERP systems as a tool to support decisionmakers can also be disrupted by the presence of departments within more dominant companies. It can affect decision-making made by management. With such a dominant department, all decisions made by management can be influenced by the dominant department. It can result in the function of the ERP system that can not run properly so that the company can not feel the benefits that should be provided by the ERP system to the company when using it. Therefore, the company can conduct research on its corporate structure. That is to ensure the division of duties and responsibilities is carried out evenly so that no department is dominant. The flow of information between departments and employees becomes clear. In addition, the company's structure must also be able to support the decision-making system from above.

Regulations, norms, and values created by the company can also support a situation conducive to the company. The regulations in the company must be well documented and communicated to employees. Such good communication needs to be done so that every employee can understand the norms, comply with company regulations, and apply the values owned by the company. That will have an impact on how employees interact with other employees. With good interaction between employees, the cooperation between colleagues can be better so as to impact the department where they work. If it is applied, then the relationship between each department can be better so that there are no more dominant departments within the company that will eventually make the corporate environment more conducive to ERP. After the ERP system is implemented, the company must also create procedures on how to use the ERP system, who can use the ERP system, what information can be used, etc. These procedures should also be well documented and socialized. Socialization of the procedure can be done by having discussions with several worker representatives and can be done again when employees conduct training on the use of the new ERP system.

\section{Ideal IT Variables}

In implementing ERP, implementation must be done through several stages. The stages of this implementation are called life cycle ERP. In order for ERP implementation to be successful, companies, especially IT departments, must perform all stages in the ERP life cycle. Therefore, all resources are required to complete all stages of the implementation project perfectly. As explained in the previous subsection, top management support is required to get all the necessary resources. Support from top management is required for ERP implementation to really get the support of all the resources needed for ERP implementation, especially financial resources. With these adequate resources, the IT department can complete the ERP implementation perfectly, so that the success of the implementation can also increase.

In addition to completing the entire project completely, resources are needed by the IT department to solve all IT problems that occur that can hinder ERP survival. One of the IT problems that occur can hinder the survival of ERP. One of the IT problems that usually occur when ERP is present is the problem of converting data from the old system to the new system. If all the resources needed by the IT department can be available, then the IT department can also convert the data well, so that the company's business processes become uninterrupted. To ensure it can be conducted trials of ERP systems using several endusers who will use the ERP system.

Another factor is one alternative to getting support from top management to put the head of IT in top management. However, this will be meaningless if the head of IT is not active to discuss with other heads of departments incorporated in the top management. The use of ERP systems should also not use IT systems that are too complex. This is so that the company's business processes are not disrupted due to IT systems. Therefore the complexity of an IT system must be adjusted to the size of the company. To support the use of ERP systems, the size of the IT department must also be considered. The size of the IT department must be balanced with the size of the company. Even if necessary, if the company has a branch office, then there 
is an IT department in the branch office in each branch office. It aims so that all IT problems that occur can be quickly responded to and resolved by the IT department. It becomes more important when ERP is implemented. If there is an IT problem related to the ERP system, the IT department must quickly respond and solve the IT problem to not interfere with the company's business process. Therefore, it is important to immediately adjust the size of the IT department to the size of the company when the company decides to implement ERP.

\section{CONCLUSION AND RECOMMENDATIONS}

First, the amount of data that is eligible in all respondents who participated in this study is $100 \%$. Based on the research obtained, obtained the value of successful ERP implementation in Indoporcelain amounted to 5.27 on a scale of one to seven. With this value, ERP implementation at Indoporcelain can be said to be quite successful but not optimal because there are still variables or conditions of the company and other problems that do not support the implementation of ERP. Compared to research conducted by Ifinedo in Finland and Estonia with a value of 4.88, the success of ERP companies is higher when compared to ERP success in Finland and Estonia.

Second, based on the correlation analysis conducted, IT variables have a stronger correlation to the value of successful ERP implementation when compared to organizational variables. But the value does not differ much and is insignificant. In organizational variables, the organizational structure is the value that contributes the most to the organization variable. As for IT variables, the highest results are obtained from the IT skill factor in the company.

Third, to increase the value of successful ERP implementation, it is necessary to make the following improvements: The main factor that should be the concern of companies to improve ERP implementation in their companies based on this research is the vision and mission of the company that must be socialized in order to maximize ERP implementation. This is the only factor in the organization variable that has the lowest value of 4.30. On IT variables still associated with the company, what needs to be improved is the size of the IT department that must be enlarged with competent people in the IT field, because the IT department in this company is very small, and with the number of personnel available, it is difficult for personnel whenever there is an error in their branch office. Therefore, this is a major concern. Then a small IT budget is also influenced by the small departments so that they make a system that is not so complex but can be used for the main interests in the company only.

Fourth, on organizational variables, the organizational structure gets the highest score of 5.88 from a scale of 7. Furthermore, top management support also contributes a value of 5.4, and also the value supports the organizational culture in companies that get a value of 5.30. Lastly, in IT variables, the value of the IT department for companies gets the largest score of 5.72; this is offset by the skills or skills of IT personnel in the company of 5.68. Then the satisfaction of the previous system also has a large value of 5.60. Satisfaction with the old system is a dangerous indication of ERP implementation in the company. However, Ifinedo's research shows that the more satisfied they are with the old system, the better they need the system.

Following the variables that affect the successful dimensions of ERP, then two suggestions need to be considered by the company for each variable. The first one is organizational variables. If the company decides to implement ERP, it is recommended that the top management fully support the implementation. The support is in funding support, information support, advice support and support for the IT team always to maximize every module created. In addition, the objectives of the implementation must be clear and must be following the vision and mission of the company. A good and transparent corporate structure will make it easier for each other to exchange information freely. It aims to make the company's condition conducive and make employees happy to work in the company and cooperate with other colleagues. The rules, norms, and values applied in the company must also be clear and well documented in order for all employees to understand them. Moreover, ERP is used according to the company's condition because ERP will impact 
the whole company. The second is IT variables. The authors' advice for the size of the IT department in the company is well balanced with the company's size so that the IT problems that occur can be solved effectively and efficiently because the purpose of using IT in the company is to make the company's activities effective. The competence of IT staff must also support how much company they handle. Then for the budget of the IT department is better adjusted to the level of complexity of the IT system in the company.

\section{REFERENCES}

Davenport, T. (2000). Mission Critical. Harvard Business School Press.

DeLone, W. H., \& McLean, R. (2003) The DeLone and McLean model of information systems success: A ten-year update. Journal of Management Information Systems, 19(4), 9-30.

Esteves, J., Pastor, J., \& Varvalho, J. (2003). Organizational and National Issues of an ERP Implementation in a Portuguese Company. IFIP (w8.2+w9.4), Athens (Greece), June 2003, 139-153.

Gable, G. G., Sedera, D. \& Chan T. (2003). Enterprise Systems Success: A Measurement Model. In: S. T. March, A. Massey \& J. I. DeGross (Eds.), Proceedings International Conference on Information Systems, Seattle, Washington: ICIS Press (AIS e-Library), 576-591.

Grover, V. \& Goslar, M. (1993). Towards an Empirical Taxonomy and Model of Evolution for Telecommunication Technologies. Journal of Information Technology, 8, 167-176.

Ifinedo, P. \& Nahar, N. (2006). Interactions between contingency, organizational IT factors, and ERP success. Industrial Management \& Data Systems (IMDS). Forthcoming. In P. E. Ifinedo, Enterprise Resource Planning System Success Assessment: An Integrative Framework. Jyväskylä University Printing House.

Ifinedo (2006). Enterprise Resource Planning System Success Assessment: An Integrative Framework. Jyväskylä University Printing House.

Khan, A. (2002). Implementing SAP with an ASAP Methodology Focus. Writers Club Press.

Ko, D., Kirsch, J. L. \& King, W. R. (2005). Antecedents of knowledge transfer from consultants to clients in enterprise system implementation. MIS Quarterly, 29(1), 59-85.

Markus, L. \& Tanis, C. (2000). The enterprise systems experience - from adoption to success. In Zmud, R.W. (Ed.), Framing the Domains of IT Research: Glimpsing the Future Through the Past, Pinnaflex Educational Resources, Inc., Cincinnati, OH, pp. 173-207.

Myers, B. L., Kappelman, L. A. \& Prybutok, V. R. (1997). A comprehensive model for assessing the quality and productivity of the information systems function: Toward a theory for information system assessment. International Resources Management Journal, 10(1), 6-25

O'Leary, D. E. (2000). Enterprise Resource Planning Systems. Cambridge: Cambridge University Press.

Shang, S. (2000). A comprehensive framework for classifying the benefits of ERP systems, in $\mathrm{H}$. Chung (ed.), Proceedings of the Sixth Americas Conference on Information Systems, Association for Information Systems, pp. 1005-1014.

Sugiyono (2009). Metode Penelitian Kuantitatif Kualitatif dan $R \& D$. Alfabeta.

Sumarna, D. L. (2006). Pengembangan Model Pengukuran Sukses ERP dan Hubungan Kausalitas Antar Dimensinya. Institut Teknologi Bandung.

Sun, A. Y. T., Yazdani, A., \& Overend, J. D. (2005). Achievement Assessment for Enterprise Resources Planning (ERP) System Implementation Based on Critical Success Factors (CFS). International Journal Production Economics, 98, 189-203.

Sutabri, T. (2004). Analisa Sistem Informasi. Andi Offset.

Themistocleous, M., Irani, Z., O'Keefe, R. M., \& Paul, R. (2001). ERP Problems and Application Integration Issues: An Empirical Survey. In R. J. Sprague (Ed.), Proceedings of Thirty-Fourth Annual Hawaii International Conference on System Sciences IEEE Computer Society. 
Thong, J. Y. L., Yap, C. S., \& Raman, K. S. (1996). Top management support, external expertise and information systems implementation in small businesses. Information Systems Research, 7(2), 248-267.

Tjahjadi, C. Y. (2008). Identifikasi Faktor Kesuksesan Implementasi Sistem ERP di Indonesia: Studi Kasus Multi-Site. Bandung: Institut Teknologi Bandung.

Uyanto, S. S. (2006). Pedoman Analisis Data dengan SPSS. Graha Ilmu.

Wixom, B. H. \& Watson, H. J. (2001). An empirical investigation of the factors affecting data warehousing success. MIS Quarterly, 25, 17-41.

Xue, Y., Liang, H., Boulton, W., \& Snyder, C. (2005). ERP Implementation Failure in China Case Studies with Implications for ERP Vendors. International Journal Production Economics, 97(3), 279-295.

Yusuf, Y., Gunasekaran, A., \& Wu, C. (2006). Implementation of Enterprise Resources Planning in China. Technovation, 26, 1324-1336. 